\title{
PERCEPCIÓN SENSIBLE Y CONOCIMIENTO DEL MUNDO NATURAL EN RENÉ DESCARTES
}

LAURA BENÍTEZ G.

INSTITUTO DE INVESTIGACIONES FILOSÓFICAS UNIVERSIDAD NACIONAL AUTÓNOMA DE MÉxICO

El nombre René Descartes, nos trae a la mente al filósofo del "cogito", nacido hace 400 años en un pequeño pueblo de la Turena, "La Haye", hoy "de Descartes". Empero, no podemos soslayar su importancia como filósofo de la naturaleza. En efecto, la física cartesiana no es un corpus independiente de conocimientos. Descaîtes la concibió fundada en la metafísica, en vista de su concepción orgánica del conocimiento, que retoma la imagen renacentista del árbol del saber. Sin embargo, no sólo fue sensible a los problemas fundamentales que se debatían en la época, como el de la homogeneidad del universo, el del movimiento, el de la infinitud del mundo, etc., sino que, particularmente, desde la perspectiva epistemológica, aporta una gran cantidad de elementos críticos, metodológicos, lógicos, etc., para la fundamentación y constitución del conocimiento del mundo natural.

Es, justo en el contexto del conocimiento de la naturaleza, que las propuestas cartesianas sobre la percepción sensible adquieren especial significado. La preocupación que motiva este análisis se podría formular así: ¿acaso el innatismo cartesiano es tan radical que todo conocimiento del mundo natural se reduce a hacer explícito, desarrollo, deducción, etc., de las ideas que la mente contiene? ¿Es que todas nuestras percepciones sensibles son deleznables por falsedad material, esto es, porque nada les corresponde en la realidad? Estas y otras preguntas semejantes hacen indispensable revisar el problema de la percepción sensible, en función de un modelo de ciencia que pretende, a la vez, ser evidente y no estar desligado de la experiencia.

\section{Acerca de la vía de reflexión epistemológica}

El planteamiento que hace Descartes de los problemas en torno al conocimiento siguen un peculiar estilo filosófico de pensamiento, cuyas características más sobresalientes, serían: 
1. La estipulación de la existencia del pensamiento como una sustancia privilegiada, al menos en dos sentidos:

A) Porque el "yo" pensante tiene un acceso inmediato a sí mismo, esto es, el autoconocimiento implica cierta transparencia epistemológica.

B) Porque este "yo" pensante o res cogitans, a pesar de estar fuertemente separado del mundo externo, esto es, ser ontológicamente independiente y diferente de la res extensa, puede acceder a su estructura más profunda y conocer las leyes generales que la rigen universalmente.

2. La estipulación de que el mundo externo es homogéneo, i.e., no es un cúmulo de diversas formas sustanciales, sino diversos modos más generales o más particulares de la única materia que constituye al universo y cuyo modo esencial es la extensión.

Tanto la separación del "yo", de entre las cosas del mundo, como la homogeneidad del universo, cuyos antecedentes se encuentran en el Renacimiento, ${ }^{1}$ se transforman en los principios filosóficos más importantes del sistema dualista cartesiano.

Para comprenderlos mejor es necesario recurrir a un modelo exegético que permita dar cuenta de este cambio, que se da en el tránsito del pensamiento tradicional al moderno.

Llamaré vía de reflexión epistemológica a un estilo de pensamiento filosófico que privilegia el conocimiento del sujeto y de sus contenidos mentales y que intenta llevar a cabo una reducción sustancial del mundo, desechando, en general, la posibilidad del conocimiento de las esencias.

La vía de reflexión, como estilo de pensamiento, puede ser compartida por varias escuelas y autores en distintos momento históricos, sobre la base de algunos supuestos fundamentales compartidos.

Definida, en esta forma general, cabe esperar que muy diversos autores, en la modernidad filosófica, hayan transitado por la vía de reflexión epistemológica. Sin embargo, las vías reflexivas no son excluyentes del todo, por lo cual, también cabe esperar que muchos autores hayan permanecido adheridos a una vía de reflexión más tradicional, así como que en un mismo autor confluyan la vía de reflexión tradicional y la nueva.

Llamaré vía de reflexión ontológica a aquella que se sustenta en la consideración de que el mundo es un cúmulo enorme de objetos diversos en esencia y grados de entidad. Para esta vía, el pensamiento

1 Cabe aclarar que en el Renacimiento se conocieron las propuestas de Juan Filópono, quien ya desde el siglo v d.C. había formulado una propuesta de homogeneización del universo que sin duda inspiró a los autores de este periodo. 
es una sustancia más entre las sustancias; y, el reto epistemológico fundamental, es la abstracción de la esencia de cada género de objetos.

El cambio, que se da en la modernidad, de los compromisos ontológicos y epistemológicos, permite acercarse al conocimiento del mundo natural con muy distintas estrategias y pretensiones de alcance.

Considero, pues, que Descartes influye de manera decisiva en el desarrollo de la vía de reflexión epistemológica, que muchos otros autores modernos habrán de seguir con sus propias e interesantes peculiaridades.

\section{Sobre la percepción sensible}

En la Segunda meditación, Descartes dice:

Finalmente, yo soy el mismo que siente, es decir, que recibe y conoce las cosas como por los órganos de los sentidos, porque en efecto, veo luz, oigo el ruido, siento calor. Pero se me dirá que estas apariencias son falsas y que duermo. Sea así, de todos modos al menos es muy cierto que me parece que veo, que escucho y que me caliento y ello es propiamente lo que en mí se llama sentir y ello, tomado precisamente así, no es otra cosa que pensar. (Meditaciones $2 \mathrm{~A} / \mathrm{T}$ $\mathrm{IX}, 23$ )

Para Descartes, si el "yo" se define como "cosa pensante", como en la Segunda meditación, que citamos arriba, entonces, la percepción sensible será una función del pensar. Sin embargo, una vez recuperado el cuerpo, el "yo", para Descartes, se refiere a la unión de dos sustancias, alma y cuerpo, por lo que la percepción sensible participa tanto de lo corpóreo como de lo mental.

Aún más, si sólo hablamos de sensación, entonces podemos describirla en términos meramente mecánicos o fisiológicos, al igual que la de los animales. Por esta razón, es muy importante tomar en cuenta que el propio Descartes hace un análisis de la percepción sensible por niveles, no exento de tensiones, pero fundamental para sus propuestas epistemológicas.

En efecto, en las Respuestas a las sextas objeciones, Descartes expone tres modos de consideración respecto a los fenómenos de la percepción sensible:

1) la perspectiva física, fisiológica o sensación;

2) la perspectiva que enlaza lo físico y lo mental en el nivel de experimentar o tener conciencia de las sensaciones;

3) la que, sobre la base de la unión mente-cuerpo, considera diversas operaciones mentales, en función de la percepción sensible. 
Para comprender mejor cuál es la certeza de los sentidos, es necesario distinguir en ellos tres clases de grados. En el primero, no debemos considerar otra cosa sino lo que los objetos externos causan inmediatamente en los órganos corpóreos; lo que no puede ser otra cosa que el movimiento de las partículas de estos órganos y el cambio de figura y situación que proviene de este movimiento. El segundo contiene todo lo que resulta inmediatamente en el espíritu, por estar unido a los órganos corpóreos y ser movido y dispuesto así por sus objetos; tales son las sensaciones de dolor, cosquilleo, hambre, sed, colores, sonidos, sabores, olores, calor, frío y otras semejantes que dijimos en la Sexta meditación, provenían de la unión y, por así decir, de la mezcla del espíritu con el cuerpo. Y finalmente, el tercero comprende todos los juicios que tenemos costumbre de hacer desde nuestra juventud con respecto a las cosas que se encuentran a nuestro alrededor, con ocasión de las impresiones o movimientos que se realizan en los órganos de nuestros sentidos. (Respuestas 6 A/T VII, 237)

Como podemos apreciar, los esfuerzos de Descartes se encaminan, por un lado, a separar los aspectos mecánicos de los intelectuales en lo que se refiere a la percepción sensible, pero, por el otro, requiere integrar ambos aspectos para dar cuenta de lo que llama segundo y tercer niveles de percepción sensible.

El primer nivel se refiere a la mera sensación, que puede explicarse, mecánicamente, como el efecto que los objetos externos causan en nuestros órganos corpóreos, por el mero choque y movimiento de las partículas materiales de los objetos, contra las de los sentidos externos.

El segundo se refiere a "tener" o "experimentar" sensaciones, esto es, se agrega el factor conciencia como fundamental, de modo que "ver" colores, "oír" sonidos, "sentir" hambre, etc., es estrictamente, tener conciencia de las sensaciones, aunque en esta propuesta Descartes no niega la base fisiológica de las mismas. Se trata de que las sensaciones se hacen conscientes, porque el espíritu está unido a los órganos de los sentidos y es afectado por sus objetos. Resulta obvio que, en esta propuesta, Descartes no se preocupa por el problema de la interacción, esto es, cómo interactúan espíritu y materia y, particularmente, cómo lo físico mueve lo mental, simplemente lo da por hecho.

En cuanto al tercer nivel, es interesante notar que Descartes habla no sólo de conciencia de la sensación, sino de los juicios que la acompañan y que nos permiten desechar prejuicios y tomar conciencia de las condiciones que afectan nuestro "tener sensaciones". Se trata, pues, de una perspectiva epistemológicamente privilegiada, que posibilita la corrección de errores, como el muy frecuente de "ver" que la vara en el agua está rota, cuando se trata de un fenómeno de refracción, producido por el cambio de medio, al pasar la vara del aire al agua. 
Desde luego, este tercer nivel de la percepción sensible o certeza de los sentidos, asociada al juicio y al razonamiento, en función del conocimiento del mundo natural, es el que más me interesa en este trabajo. Con todo, cabe recordar que, tanto en el segundo como en el tercer niveles de percepción, donde interviene la conciencia, las sensaciones no son, en realidad, otra cosa que ideas en la mente. Podemos entonces preguntar, cómo se vinculan éstas (las ideas), con los objetos de nuestros sentidos que, como Descartes dice, son las causas de esas afecciones nuestras. Estamos de lleno en el problema de la representación sensorial.

\section{Las ideas de sensación: ¿semejanzas o signos?}

En torno a la Tercera meditación se han suscitado muchos debates, debido a que Descartes no presenta un criterio único en relación con las ideas de sensación, que unas veces considera como imágenes de las cosas (tamquam imaginis rerum) y otras "tales como de las cosas" (tamquam rerum), aludiendo, en ambos casos, a la representación. Con todo, nunca sabemos en qué consiste esa representación de las cosas pero, lo que sí se aclara, es que la representación no es semejanza.

Luego, el principal y más ordinario error que puede encontrarase consiste en que juzgo que las ideas que están en mí, son semejantes a las cosas que están fuera de mí. (Meditaciones III A/T IX, 29)

$\mathrm{Al}$ acentuar la desemejanza entre las ideas (representantes) y las cosas (representadas), Descartes torna laxa la relación causal entre las cosas fuera de la mente como causas y las ideas en la mente como sus efectos, lo cual favorece interpretaciones antirrealistas de la percepción sensible en este autor. Sin embargo, hay que entender que, para Descartes, las ideas no son semejanzas de los objetos en el sentido escolástico tradicional, mucho menos especies intencionales que se desprendan de los objetos y "penetren" nuestros sentidos al estilo epicúreo.

Luego, aunque los objetos de los órganos de los sentidos son las causas de nuestras ideas sensibles, qua modificaciones de la mente, hay que saber que ni todas las ideas son imágenes ni, las que lo son, son realmente semejantes a las cosas porque:

hay muchas otras cosas, no imágenes, que pueden excitar nuestro pensamiento como, por ejemplo, los signos y las palabras que de ninguna manera se parecen a las cosas que significan. (Dióptrica A/T VI, 112)

Queda claro que, al menos, algunas ideas lo son de signos, pero estas ideas, sean de imágenes o de signos, constituyen nuestra percepción sensi- 
ble y por ello guardan cierto vínculo con las cosas o propiedades que nos representan. En todo caso, lo importante es saber si estas relaciones, con el mundo externo, son siempre indirectas, entendiendo las ideas como entidades que median nuestro conocimiento de las cosas, o si las ideas son una forma de la existencia de las cosas, de donde la expresión, "tales como de las cosas", parece aludir a las ideas como el modo de existencia "objetivo" i.e., en el entendimiento, de las propias cosas. En el primer caso se da lugar a la interpretación más idealista de la teoría cartesiana de las ideas; en el segundo, en cambio, se abre la posibilidad a diversas interpretaciones realistas, no ingenuas, como la del realismo indirecto.

Para poder dar alguna respuesta a esta cuestión es importante seguir la clasificación que Descartes hace en los Principios, de las propiedades que pertenecen al pensamiento, como la percepción, la volición y sus modos; las que pertenecen a la extensión como el tamaño, la figura, el movimiento, la divisibilidad, etc. y, finalmente, las de las mentes corporeizadas como son los apetitos (hambre, sed); las pasiones (tristeza, amor); las sensaciones (color, sonido, dolor, sabor, etcétera).

Normalmente, se ha interpretado que la percepción sensible se limita a la captación de sensaciones como color, sabor, sonido, etc., que son para Descartes, al menos en la Dióptrica, la "traducción" que nuestros sentidos hacen, de la estructura del mundo natural, que no se reduce sino a corpúsculos de materia en movimiento o reposo. Así pues, como "traducciones", nuestras sensaciones de olor, color, etc., no nos proporcionan las propiedades auténticas de las cosas, sino que son una especie de "interpretación" que nuestros ojos, oídos, lengua, tacto, etc., hacen del movimiento de las partes (cfr. Dióptrica AVT VI, 131). Dicho de otro modo, particularmente estas sensaciones son ideas oscuras y confusas que no nos revelan la estructura profunda de lo real, pero indirectamente nos permiten saber que hay algo fuera de nuestra mente, aunque no nos dicen cómo es ese algo.

4. La percepción de las propiedades mecánicas de los objetos y el conocimiento del mundo natural

Entre las aportaciones más interesantes de los últimos diez años, acerca de si la sensibilidad proporciona o no algún conocimiento del mundo natural en Descartes, se haya la de Ann Mackenzie. ${ }^{2}$ Esta autora hace una distinción entre sensaciones que remiten a las propiedades auténticas de los objetos y sensaciones que sólo son ideas en la mente o modificaciones del espíritu.

2 Ann Mackenzie: "Descartes on Sensory Representation: a Study of the Dioptrics" en Canadian Journal of Philosophy, vol. 16, 1988 y en otro texto más reciente, "The Reconfiguration of Senșory Experience", editado en la antología de John Cottingham: Reason, Will and Sensation: Studies in Descartes' Metaphysics. 
Siguiendo una clasificación tradicional, Mackenzie nos recuerda que los sensibles propios son las sensaciones que obtenemos por un solo sentido, en tanto que los sensibles comunes son las sensaciones que se dạn por más de un sentido.

Nótese que, al aplicar esta clasificación a Descartes, los sensibles propios como el color, el sabor, etc., resultan ser esas propiedades que el filósofo francés no considera como auténticas de los objetos, sino como meras ideas oscuras y confusas e incluso materialmente falsas, puesto que a ellas no corresponde nada en la realidad. En tanto que los sensibles comunes, como el tamaño, la figura, la velocidad, etc., son las propiedades auténticas de los objetos macroscópicos. Mackenzie las llama propiedades sensibles mecánicas.

Tanto en El mundo o tratado de la luz, como en los Principios, parte IV, Descartes propone que las partículas imperceptibles de los cuerpos tienen las propiedades de tamaño, figura y movimiento. Esto sugiere que, para Descartes, hay uniformidad en el universo, al considerar que la configuración y el comportamiento de la materia son idénticos tanto en el nivel micro como en el nivel macro. Aquí lo importante es que, en el nivel macro, percibo las propiedades mecánicas por los sentidos, aunadas a ciertas operaciones mentales y, en el nivel micro, jamás las percibo sensiblemente, sino que las infiero, así de mi idea innata de extensión, de la cual deduzco sus modos generales: tamaño, figura, velocidad, etc., como de mi percepción sensible de modos particulares: esta figura, este movimiento, etc., que me sirven de análogo para concluir lo que sucede en el mundo micro.

Si intentamos unir ahora la propuesta de Mackenzie con la clasificación cartesiana de la percepción sensible, nos damos cuenta de que, para los sensibles propios, basta con la conciencia de la sensación; así, tenemos sensación de color, sabor, etc.; sin embargo, los sensibles comunes no sólo requieren de más de un sentido, como Mackenzie lo propone, sino que necesitan, por parte de la mente, de bastante más que la mera conciencia. En efecto, requerirán de juicios y razonamientos, tal como lo señala Descartes en las Sextas respuestas, con respecto al tercer nivel de percepción sensible.

Si examinamos lo dicho hasta ahora, nos damos cuenta de cuán lejos nos encontramos de la interpretación sobre percepción sensible que se limita a la Segunda meditación; en efecto, ahí la percepción era sólo facultad de la mente, una pura función del pensar. En la Dióptrica, la perspectiva sobre el problema de la percepción se dirige a una explicación mecánica y fisiológica. Finalmente, en los Principios y en las Sextas respuestas, es donde más se afina la explicación sobre la percepción aludiendo, tanto a los aspectos fisiológicos, como a los intelectuales. 
La interpretación de Mackenzie nos da un elemento más; en efecto, nos dice cuándo la percepción sensible aporta o no conocimiento sobre el mundo natural. Evidentemente los sensibles propios no nos dicen cómo es el mundo natural en tanto que los sensibles comunes sí lo hacen. Me propongo, para finalizar, dar una explicación de qué es lo que determina que Descartes discrimine unos perceptos sensibles y elija otros como las verdaderas propiedades de objetos. Al hacerlo quiero mostrar que en la percepción sensible, con contenido cognitivo, intervienen más de un sentido y más de una operación mental; en efecto, se requieren ciertos recortes teóricos a través de los cuales Descartés lleva a cabo la elección de las "auténticas" propiedades de los objetos.

5. El marco teórico cartesiano y las propiedades geométrico-mecánicas de los objetos

La crítica cartesiana, entendida como parte de la vía de reflexión epistemológica, provee al investigador de una dosis razonable de escepticismo que busca prevenirlo contra los errores más comunes, tanto de la sensibilidad, como del entendimiento. La nueva ciencia luchó por ir más allá de la explicación teórica del sentido común; sin embargo, tampoco quiso caer en las ficciones especulativas. Es justo en esta perspectiva donde cobra importancia el problema de la percepción sensible, en función del conocimiento científico del mundo natural.

Por supuesto, no se trata de recuperar cualquier dato, sino sólo aquellos que, dentro de ciertos marcos teóricos, pueden resultar verdaderamente explicativos.

Considero que, en el caso de Descartes, el recorte de datos útiles para la explicación científica tiene que ver, en primer término, con su propuesta ontológica de base, esto es, con su concepción de sustancia extensa como diversa e independiente del pensamiento. A este respecto dice en los Principios:

Y la principal distinción que encuentro entre todas las cosas es, que las unas son intelectuales, es decir, son sustancias inteligentes o bien propiedades que pertenecen a esas sustancias y las otras son corpóreas, es decir, son cuerpos o bien propiedades que pertenecen a los cuerpos. (Principios, 1 A/T VIII, 53)

Por otra parte, para Descartes hay atributos esenciales que constituyen la naturaleza de cada género sustancial: la extensión es el atributo esencial de la sustancia corpórea y, el pensamiento, el de la res cogitans. La extensión, como propiedad fundamental de la materia, no sólo la homogeneiza, esto es, determina que, en todo el universo, hay una sola esencia para todos 
los cuerpos u objetos materiales, sino que le acarrea, por definición, dos importantes propiedades geométricas: la divisibilidad infinita y la extensionalidad ilimitada. Esto significa que, la geometrización de la materia, se da en función del recorte matemático-geométrico que, a su vez, se cnlaza con el marco teórico ontológico cartesiano. Así, este segundo recorte o marco conceptual geométrico-matemático, que Descartes busca que encuentre su lugar en el más amplio marco teórico, ontológico, le permite transitar, de la concepción general y abstracta de res extensa, a la más específica y geométrica de materia qua extensión, divisible en principio al infinito y extendible, también en principio, en forma ilimitada.

A partir de esta propuesta lo interesante es ver cómo encarna esta concepción geométrico-matemática de la materia en el universo físico, esto es, tratar de analizar los conceptos básicos de su marco teórico físico.

Para comenzar podemos retomar lo que Descartes dice en El mundo o tratado de la luz acerca de la divisibilidad de la materia:

la primera diferencia que deseo que consideren y que piensen para este cfecto, es que cada cuerpo puede ser dividido en partes sumamente pequeñas. No deseo determinar si su número es infinito o no, pero al menos es cierto que, desde la perspectiva de nuestro conocimiento, es indefinido y que podemos suponer que hay muchos millones en el más pequeño grano de arena que pueda ser percibido por nuestros ojos. (El mundo N/T XII, 412)

Como puede observarse, Descartes propone aquí las bases del corpuscularismo al señalar no sólo la capacidad en abstracto que la materia, como extensión, tiene para dividirse, sino al proponer que los cuerpos concretos del universo, incluso el más pequeño grano de arena, pucden divirse en partes muy pequeñas; aún más, imperceptibles. Me parece que podemos apreciar cómo Descartes lucha por hacer compatible el marco tcórico geométrico de la materia extensa con el físico de la divisibilidad material, de facto, en el corpuscularismo. Sin embargo, queda un problema por resolver. ¿Puede el corpuscularismo aceptar, sin más, la divisibilidad de la materia sin restricción? ¿Puede Descartes asumir la divisibilidad infinita strictu sensu?

Me parece que el párrafo anteriormente citado de El mundo, mucstra la indecisión de Descartes, quien sólo habla de partes muy pequeñas y no desea comprometerse con el problema de la infinitud. Con todo no puede negarse el esfuerzo que el autor realiza por acotar el problema de la divisibilidad, desde la perspectiva física, al establecer que no hay cuerpos cuya íntima naturaleza les impida dividirse, esto es, al rechazar implícitamente el atomismo.

Por otra parte, el mismo recorte o marco teórico-geométrico lo lleva a la postulación del pleno pues, siguiendo a Aristóteles, si la materia es 
tridimensional y el espacio no es sino la propiedad volumétrica de la materia, no puede haber espacio externo, i.e., fuera de la materia ya que éste también será tridimensional, por tanto, no penetrable por los cuerpos; en consecuencia, el espacio no puede separase del cuerpo y el espacio vacío es inconcebible. Nuevamente, en $E l$ mundo nos dice:

Pero concibamos la materia como un verdadero cuerpo, perfectamente sólido, que llena igualmente todos los largos, anchos y profundidades de este gran espacio, en medio del cual hemos detenido nuestro pensamiento, de manera que cada una de sus partes ocupe siempre una parte de este espacio, de tal modo proporcionada a su tamaño, que no podría llenar una más grande ni encerrarse en una más pequeña, ni tolerar que mientras permanece en ella, alguna otra tome su lugar. (El mundo A/T XII, 430)

En Descartes, el reforzamiento del pleno es mayor en vista de que el espacio no es tan sólo una propiedad entre otras de la materia como para Aristóteles, sino que es su propiedad esencial, de modo que materia es extensión o espacio, de acuerdo con el marco teórico-geométrico del que parte pero, además, al integrar su teoría física, en este caso, particularmente el plenismo, se ve llevado a decir que, en el universo físico, donde hay espacio, necesariamente hay cuerpo.

Creo que podemos apreciar con claridad este paso de la propuesta abstracta geométrica al marco teórico físico. Vemos cómo la teoría geométrica limita el recorte físico cartesiano que se concreta en:

1. Una teoría corpuscular en relación con la división de la materia.

2. Un propuesta plenista que excluye el vacío.

3. Una teoría mecanicista en relación con el movimiento de los cuerpos.

Todo ello se refleja en El mundo donde Descartes nos dice:

agreguemos a esto que esta materia puede dividirse en todas las partes y según todas las figuras que podamos imaginar; y que cada una de sus partes es capaz de recibir en sí todos los movimientos que podamos también concebir. Y supongamos, además, que Dios la divide verdaderamente en muchas partes determinadas, las unas más grandes, las otras más péqueñas; las unas de una figura, las otras de otra, tal como nos plazca forjarlas. No, que las separe, por ello, la una de la otra, de manera que se dé algún vacío entre dos; sino pensemos que toda la distinción, que hace allí, consiste en la diversidad de los movimientos que les da, haciendo que, desde el primer instante en que son creadas, las unas comiencen a moverse de un lado y las otras de otro, las unas más rápido y las otras más lentamente (o incluso, si así lo quieren, permanezcan sin moverse) y que continúen después su movimiento ateniéndose a las leyes ordinarias de la naturaleza. (El mundo AVT XII, 431) 
En cuanto al corpuscularismo, cabe aclarar que, en principio, la materia es divisible al infinito; sin embargo, de facto, la división haya sus límites en las leyes del movimiento decretadas por Dios y que Descartes llama leyes de la naturaleza. Esto marca claramente la diferencia entre el marco teórico geométrico y el físico. De hecho, el límite de la división se evidencia en las tres clases de partes materiales que constituyen a los elementos (fuego, aire y tierra) del universo. Sin embargo, aunque los tres elementos tienen la misma naturaleza material, con lo cual se mantiene la homogeneidad del universo, la "diferencia" está dada por el tamaño, la velocidad y la figura de las partes componentes de cada elemento.

El corpuscularismo le permite a Descartes proponer que la materia está, de hecho, y no sólo de manera abstracta e hipotética, dividida en partes, mismas que, por naturaleza son divisibles aunque encuentran el límite a su división en las leyes naturales.

Dentro de este mismo recorte teórico-físico, Descartes desarrolla una teoría mecánica que le permite entender el conjunto de partes materiales como partes en movimiento o reposo, como meros estados posibles de la materia. Así, la materia no tiene movimiento intrínseco pues es inerte, de donde estas partes no son sino móviles que transportan el movimiento. Aquí caben dos aclaraciones:

a) El movimiento no es, para Descartes, una fuerza que pueda darse al margen de las partes materiales; en este sentido, puede entenderse como una propiedad de la materia.

b) Sin embargo, el movimiento no es algo que la materia misma origine o produzca, pues Dios creó materia y movimiento al mismo tiempo, pero la materia no es más que el vehículo o móvil que transporta el movimiento, sin que por ello lo produzca.

Naturalmente, los movimientos de las partes están regidos por las leyes de la naturaleza o leyes del movimiento, la de inercia, la de conservación del movimiento y la del choque y son, estas mismas leyes, las que explican que las partes lleguen a un límite real de división para constituir los tres elementos "funcionales", todos de la misma materia, por tanto de la misma naturaleza, pero con diferentes figura, tamaño y velocidad de sus partes componentes (cfr. El mundo A/T XI, 424).

Una vez explicitados los marcos teóricos (ontológico, matemático y físico), que le sirven a Descartes de referencia para la selección de los datos propios del conocimiento científico del mundo natural, aparece como consistente la elección que hace de propiedades cuantificables o propiedades geométrico-mecánicas, como la figura, el tamaño, el peso, la distancia, etc., 
puesto que se trata de un recorte acorde con los marcos propuestos. Así, refiere en el El mundo:

todas las formas (naturalezas) de los cuerpos inanimados pueden explicarse sin que se necesite suponer para tal efecto ninguna otra cosa, en su materia, que el movimiento, el tamaño, la figura y el acomodo de sus partes. (El mundo $\mathrm{A} / \mathrm{T} \mathrm{XI}, 425)$

En consecuencia, propiedades como el color, el sonido, la textura, etc., quedan por completo fuera del recorte teórico y son datos que no pueden ni manejarse ni interpretarse dentro de los marcos admitidos, por lo que resultan oscuros, confusos, no pertinentes e incluso falsos en el ámbito del conocimiento científico.

\section{Conclusiones}

Como puede apreciarse, mi intención es analizar el significado de la percepción sensible, específicamente referida a lo que he llamado propiedades "geométrico-mecánicas" de los objetos, las que, según Descartes, bastan para el conocimiento de los modos particulares de la extensión que son los cuerpos físicos.

Espero haber mostrado, hasta donde es posible, que tales propiedades se perciben sensiblemente, aunque pertenecen al tercer nivel de percepción que implica para Descartes la capacidad de juzgar, argumentar, sopesar, evidenciar, etc., según lo refiere en las Sextas respuestas.

Por otra parte, estas propiedades, como lo he formulado, implican ciertos recortes teóricos previos. Descartes intentó que estas teorías, la ontológica, la matemática y la física, fueran compatibles entre sí, con lo cual tendría una propuesta consistente y sistemática.

En mi opinión, en Descartes, las propiedades geométrico-mecánicas quedan definidas por las propuestas teóricas que él explicita. Así, hay una lógica de los enlaces entre, por ejemplo, la res extensa, que es un concepto ontológico y la materia qua extensión, que es un concepto geométrico y, de igual manera, puede apreciarse entre las propiedades geométricas como divisibilidad y extensionalidad y la contraparte física: plenismo y corpuscularismo.

En suma, el realismo indirecto de Descartes pasa por la postulación de una sustancia extensa que la mente tiene ante sí como una idea clara y distinta, que no se conoce por los sentidos aunque gracias a ellos pueda afirmarse como existente. Además, fincados en esta idea innata de extensión, podemos conocer sus modos particulares, esta figura, este cuerpo, esta velocidad, etc., a través de la percepción sensible de tercer nivel en la cual, no sólo se requiere de la participación de varios sentidos, sino de los juicios 
del entendimiento y yo agrego que, su valor como datos de la experiencia, para la constitución del conocimiento científico, les es conferido por las teorías aceptadas. De modo que tales datos no tienen valor intrínseco o independiente (como auténticos y absolutos descriptores de la naturaleza), pues tamaño, figura, velocidad y movimiento son los descriptores de la mecánica cartesiana.

\section{Colofón}

Pensar el universo en términos de extensión geométrica culmina en dos curiosas paradojas: la división constante de la materia, que hace imposible la constitución de los cuerpos materiales, por lo cual Leibniz rechazó la propuesta cartesiana y la consideración del sólido continuo que hace inexplicable el movimiento, en opinión de algunos comentaristas. Así parecería que el corazón geométrico de la física cartesiana la hace, en principio, inviable. Sin embargo, Descartes trata de salvar las paradojas a través de dos propuestas fiscas concretas: la teoría de los elementos y las leyes del movimiento. En todo caso, estos problemas siguen sujetos al debate, por lo cual hacer explícitos los marcos teóricos que le sirvieron de base, permite establecer de qué forma y hasta dónde, Descartes enriqueció la vía de reflexión epistemológica.

\section{BIBLIOGRAFÍA}

Descartes, R., CEuvres, Charles Adam \& Paul Tannery (comps)., Léopold Cerf, París, 1913.

_-, CEuvres philosophiques, Garnier Frères (comp.); París, 1963.

_- El mundo o tratado de la luz, trad. Laura Benítez, IIf unAm, México, 1986.

Benitez, Laura, El mundo en René Descartes, IIF-unam, México, 1993.

_- "La percepción sensible en René Descartes", en Benítez, Laura y José Antonio Robles (comps)., Percepción: colores, irunam, México, 1993.

_-, "La vía de las ideas", en Enciclopedia iberoamericana de filosofía, t. VI, Trotta, Madrid, 1994.

Cottingham, John, Descartes, trad. Laura Benítez et al., FFYL-UnAM, México, 1995.

Kenny, Anthony, Descartes. A Study of His Philosophy, Random House, Nueva York, 1968.

Mackenzie, Ann, "Descartes on Sensory Representation: a Study of the Dioptrics" en Canadian Journal of Philosophy, vol. 16, 1988.

- "The Reconfiguration of Sensory Experience", en Reason, Will and Sensation: Studies in Descartes Metaphysics, John Cottingham (comp.), Oxford Clarendon Press, 1994. 
Scott, J.F., The Scientific Work of René Descartes, Taylor \& Francis, Londres, 1976. Williams, Bernard, Descartes. El proyecto de la investigación pura, trad. Laura Benítez, IIF-unam, México, 1995.

Wilson D., Margaret, Descartes, trad. José A. Robles, uF.unam, México, 1989.

Yolton, John, Perceptual Acquaintance from Descartes to Reid, University of Minnesota Press, Minneapolis, 1984. 